\title{
The new design of the wood stove based on the numerical analysis and experimental research
}

\author{
Przemysław Motyl ${ }^{1, *}$, Marcin Wikło ${ }^{1}$, Julita Bukalska ${ }^{2}$, Bartosz Piechnik ${ }^{2}$ and Rafat \\ Kalbarczyk $^{2}$ \\ ${ }^{1}$ Kazimierz Pulaski University of Technology and Humanities in Radom, Faculty of Mechanical \\ Engineering, Poland \\ ${ }^{2}$ Kratki.pl, Marek Bal, Wsola, Poland
}

\begin{abstract}
In Europe, especially in Poland, wood-fired stoves remain one of the most popular renewable household heating. The use of wood logs in small-scale units stoves are expected to increase substantially. The work proposes a comprehensive approach to modify the design of wood stoves with heating power up to $20 \mathrm{~kW}$, including design works, simulations, and experimental research. The article also presents the numerical study of a combustion process including fluid flow, chemical combustion reaction, and heat exchange in the wood stove. The retrofit enhanced a more stable heat release from the wood stove, which increased efficiency and reduction of the harmful components of combustion.
\end{abstract}

\section{Introduction}

The combustion of wood remains one of the most popular sources of renewable energy in domestic appliances. The growing interest in renewable energy resources and total pollution emissions reduction is raising the research efforts in this well-known energy conversion process. The combustion of wood releases the same amount of carbon dioxide as absorbed by plants from the atmosphere and for this reason biomass does not contribute to the greenhouse effect.

The use of hearth type fireplace inserts with manual fuel loading causes a high risk that designed installations in accordance with the requirements of the relevant standards (given in the European document - Ecodesign) may not meet the environmental requirements. Increasing environmental standards contributes to continuous work aimed at improving the performance of all devices admitted to trading in the EU. Fireplace inserts are characterized by simplicity of construction. Nevertheless, intensive research works in various areas connected with the fireplace are observed. Some of the works are related to the modification of refractory materials used for the lining of combustion chambers, or the construction of external fireplace inserts [1].

The simplicity of design does not exclude work related to new, own air distribution solutions in the combustion chamber, which is crucial for ensuring minimum $\mathrm{CO}$ emissions [2]. The specificity of the product, which are fireplace inserts, as well as the increasingly

\footnotetext{
* Corresponding author: p.motyl@uthrad.pl
} 
popular design of fireplace inserts for individual consumer requirements results in the need for continuous design work and rapid prototyping of new construction solutions. Detailed rules for the admission to the sale of new constructions are defined by national and European standards. Numerical modelling is becoming an important element of time limitation in the design of new constructions with still-tightened environmental standards. The process of numerical modelling of combustion processes and heat exchange in heating installations with manual fuel loading meets a number of problems related to the work cycle and the lack of automation of the process itself. The authors of papers [3-5] suggest different way numerical calculation method for fireplaces up to $20 \mathrm{~kW}$. Paper [3] proposed a method for modelling combustion processes in the fireplace, taking into account solid and volatile components as well as moisture naturally occurring in the wood. In [4], a different approach was chosen and the main assumption was to focus only on flow and heat exchange, treating wood logs as a source of heat and gas. The authors argued that optimal heat exchange is the main determinant of the high efficiency of the heating installation. In [5], the fireplace insert was modelled on the assumption that only volumetric and gas reactions should be considered. This simplification may be correct due to the composition of the wood, which in $70-80 \%$ consists of volatile parts.

The aim of this study is to optimize a fire-place to lower its environmental impact. Experimental and computational activities were performed to determine the possible improvements of total environmental impact of a wood-open fireplace. Two models of fireplaces will be discussed, both with the same power and with only a difference relative to the geometry.

\section{Formulation of the problem}

The first numerical model was prepared for a fireplace insert with manual fuel loading and lockable furnace door with dimensions of 930x630x490mm (Fig. 1). According to a construction data a nominal power is $12 \mathrm{~kW}$ and thermal efficiency of $70 \%$. The walls were made of s355 steel, the lining of the combustion chamber was chamotte, and the deflector was made of vermiculite. For the proposed fireplace insert, a numerical simulation was designed to reflect the real operating conditions of the installation. From the simplified geometry of the fireplace insert, a solid was extracted as the computational domain and 4 cuboidal elements were added, being a model of wood logs (Fig. 1b). For the prepared geometry, a tetrahedral numerical grid was prepared (Fig. 1c) with a size of approx. 4 million elements. For modelling combustion processes, the Finite-Rate / Eddy-Dissipation model [6] was used with the system of equations (1-6); two-variant turbulence model k- $\varepsilon$, where: $\mathrm{k}$ kinetic energy of turbulence, $\varepsilon$ - dissipation rate [6] and radiation model - DO [6]. Both in the simulation and during the experiment, it was assumed that the fuel is deciduous wood, hornbeam with the composition given in table 1 . In order to mimic the wood log in the model, it was assumed that it consists of:

- the outer part, which is the source of gas corresponding to the part of the volatile component of the wood. Volumetric reactions represent equations 1-2.

$$
\begin{gathered}
\mathrm{C}_{1.09} \mathrm{H}_{2.1} \mathrm{O}_{0.91} \mathrm{~N}_{0}+0.617 \cdot \mathrm{O}_{2} \rightarrow 1.097 \cdot \mathrm{CO}+1.054 \cdot \mathrm{H}_{2} \mathrm{O}+0 \mathrm{~N}_{2} \\
\mathrm{CO}+0.5 \cdot \mathrm{O}_{2} \rightarrow \mathrm{CO}_{2}
\end{gathered}
$$

- the inner part corresponding to the part of the solid component of the wood, on the surface of which the reactions described by the equations take place 3-6.

$$
\mathrm{C}(\mathrm{s})+0.5 \cdot \mathrm{O}_{2} \rightarrow \mathrm{CO}
$$




$$
\begin{gathered}
\mathrm{C}(\mathrm{s})+\mathrm{CO}_{2} \rightarrow 2 \mathrm{CO} \\
\mathrm{C}(\mathrm{s})+\mathrm{H}_{2} \mathrm{O} \rightarrow \mathrm{H}_{2}+\mathrm{CO} \\
\mathrm{H}_{2}+0.5 \cdot \mathrm{O}_{2} \rightarrow \mathrm{H}_{2} \mathrm{O}
\end{gathered}
$$

The fuel mass assumed in the model was divided into 3960 seconds, which corresponds to 66 minutes of combustion in real conditions. When defining the model, it was assumed that: vacuum at the outlet to the chimney was equal to $-10 \mathrm{~Pa}$; fuel weight in the 66 minutes of the burning cycle was equal to $3,92 \mathrm{~kg}$ and the value of the throttle open was $50 \%$.

Table 1 Basic properties of wood

\begin{tabular}{|c|c|}
\hline Item & Value \\
\hline \multicolumn{2}{|c|}{ Proximate analysis [wt $\%$ ] } \\
\hline Moisture & 13,00 \\
\hline Volatile matter & 73,08 \\
\hline Fixed carbon & 13,92 \\
\hline Ultimate analysis [wt $\%$ ] DAF \\
\hline Carbon & 52,91 \\
\hline Hydrogen & 5,95 \\
\hline Oxygen & 41,14 \\
\hline
\end{tabular}

In the next step, a measurement was made on a laboratory bench equipped with: (i) a flue gas analyzer recording the negative pressure, temperature, flue gas composition $\left(\mathrm{CO}, \mathrm{CO}_{2}\right.$, $\mathrm{O}_{2}, \mathrm{NO}$ ) in the chimney at a set distance from the outlet from the fireplace insert (Fig. 2a); (ii) a thermal imager registering the temperature on the surface of the walls and on the glass of the fireplace insert (Fig 2b, 2c); (iii) a set of thermocouples recording temperature at the walls in the furnace chamber (Fig. 2a, Fig. 4). Measurements were made throughout the duration of smoking - an experiment that was carried out in accordance with the standard [7].
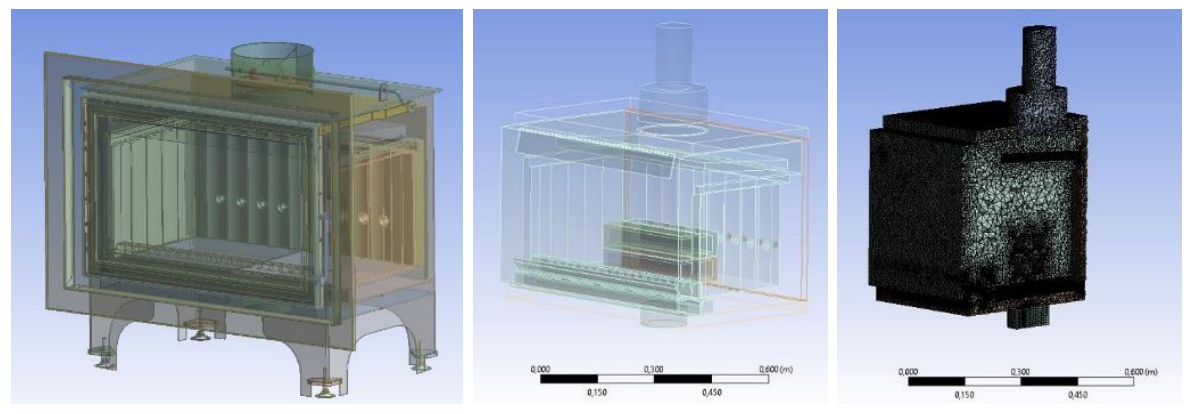

Fig. 1. View of the fireplace insert, wood model and tetrahedral numeric grid (case 0) 

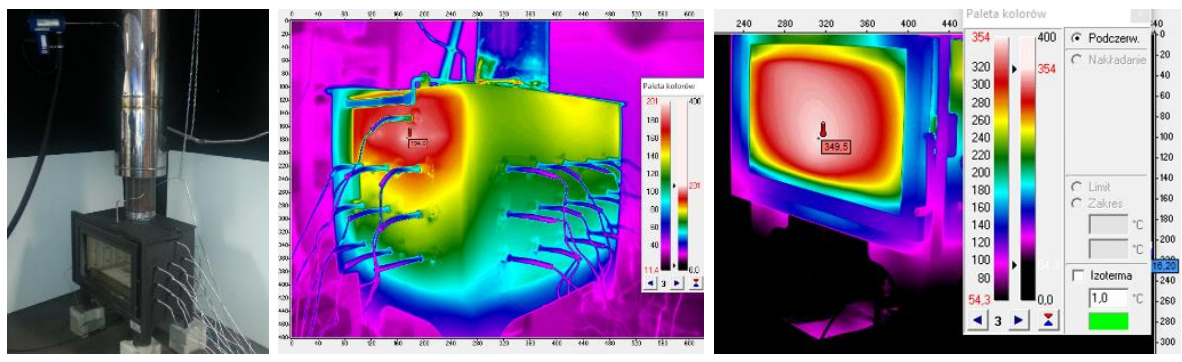

Fig. 2. Testing bench facility (fireplace with mounted thermocouples) and view from thermal imaging camera
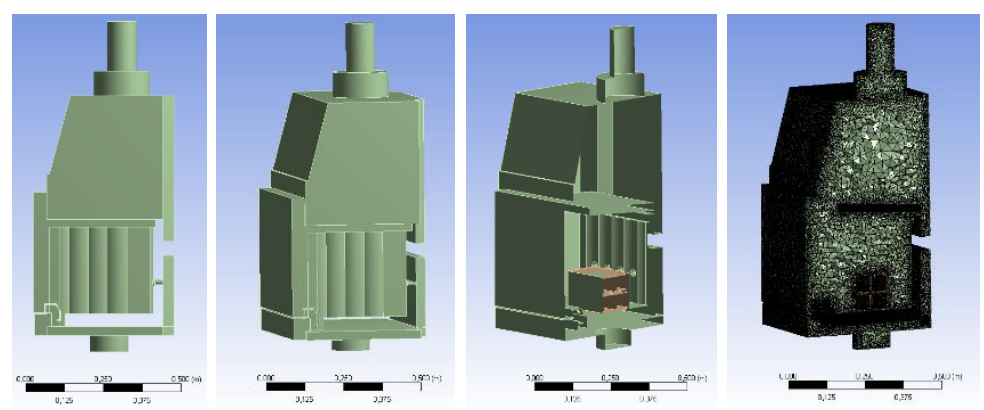

Fig. 3. View of the modification of fireplace insert, wood model and tetrahedral numeric grid (case 1)

\section{Simulation and results}

The degree of simplification of the numerical model required conducting a parallel experiment at the laboratory stand. Two sets of data were analyzed, i.e. the composition of exhaust in the chimney, as well as the temperature values indicated by the thermocouples (see Figure 4). Comparing the results of the experiment with the results of the simulation, the data from the 45 th minute of the experiment was adopted, because during the abovementioned 66 minutes of smoking between 15 and 45 minutes, the operating conditions of the heating system are stabilized. Both the emission of exhaust gases and the temperature at the measuring point of the flue pipe were at a stable level. Table 2 presents the results of measurement and simulation in the chimney (average values, case 0 and case 1). These are the results for the outlet plane to the chimney. In addition, the temperature values for three thermocouples located as was depicted in Fig. 4 were compared. It is worth noting that the individual values are at a similar level and are subject to several per cent differences. Such differences may be acceptable considering the model simplifications made and the complex nature of the phenomena occurring in the said installation. The next stage of the work was to introduce construction changes leading to higher device efficiency. Based on the results of measurements made and the results of simulations obtained at the stage of preparing the numerical model, a structural variant involving the change of the flue geometry was analyzed, which task is to extend the route of the flue gas and create an additional surface that ensures the exchange of heat with the surroundings by swirling the exhaust stream. 

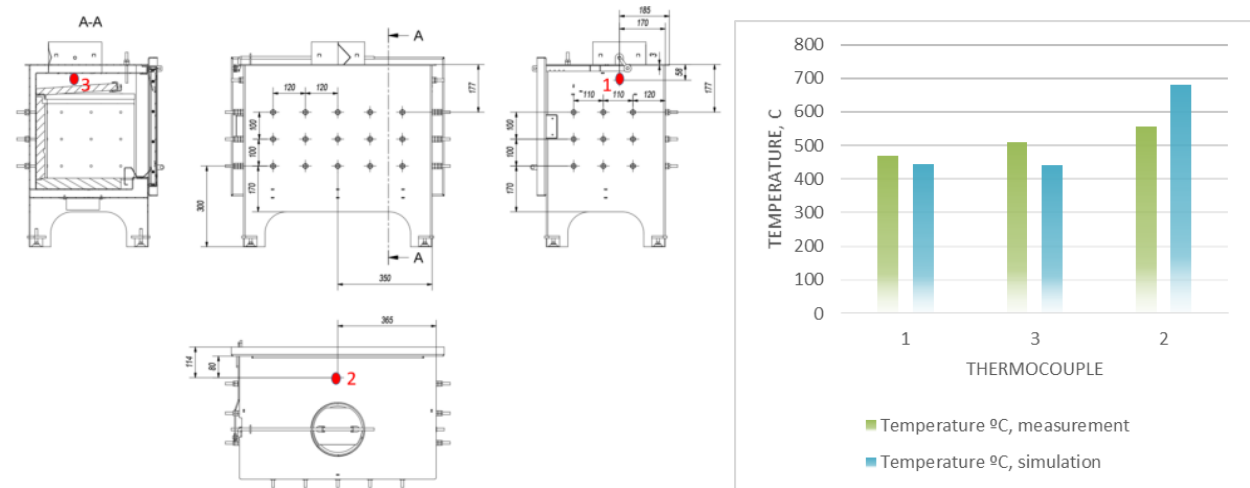

Fig. 4. Location of the thermocouples and temperature values $\left({ }^{\circ} \mathrm{C}\right)$ obtained from measurement and simulation (case 0)

Table 2. Comparison of measurement and simulation data in the chimney

\begin{tabular}{|c|c|c|c|}
\hline & $\begin{array}{c}\text { Experiment } \\
\text { (case 0) }\end{array}$ & $\begin{array}{c}\text { Simulation } \\
\text { (case 0) }\end{array}$ & $\begin{array}{c}\text { Simulation } \\
\text { (case 1) }\end{array}$ \\
\hline Temperature, ${ }^{\circ} \mathrm{C}$ & 415 & 447 & 401 \\
\hline Mole ratio $\mathrm{O}_{2}, \%$ & 12,3 & 10,7 & 10,0 \\
\hline Mole ratio $\mathrm{CO}_{2}, \%$ & 8,1 & 8,5 & 8,9 \\
\hline Mole ratio, $\mathrm{CO} \%$ & 0,1 & 0,0 & 0,0 \\
\hline Vacuum, $\mathrm{Pa}$ & 9,9 & 10 & 10 \\
\hline
\end{tabular}
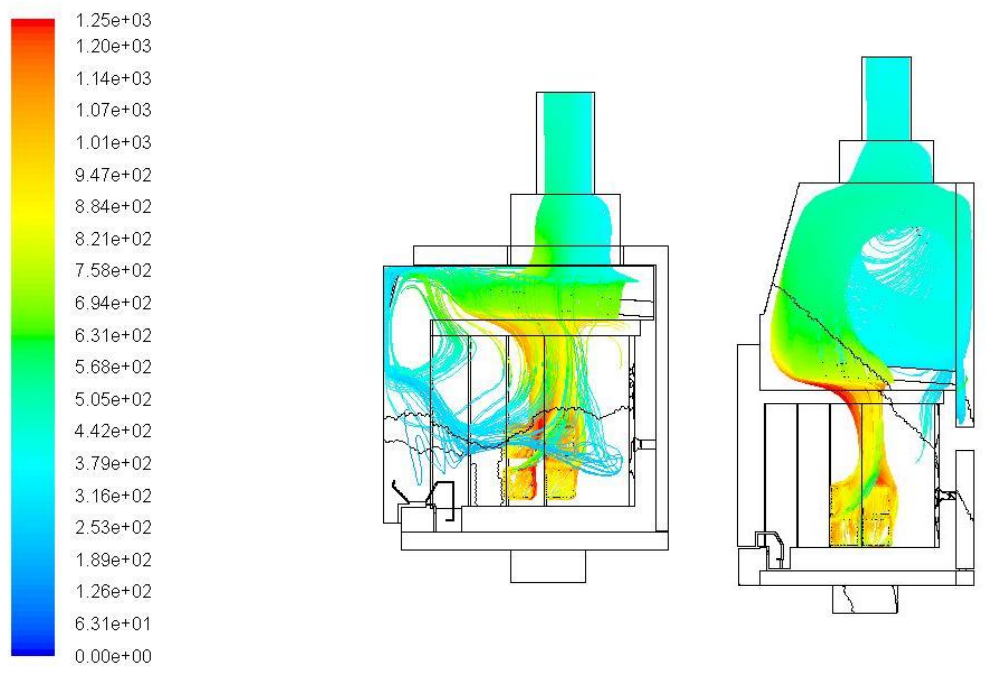

Fig. 5. View of the gas molecules path and temperature distribution $\left({ }^{\circ} \mathrm{C}\right)$ in the combustion chamber of the fireplace insert (case 0 and case 1) 

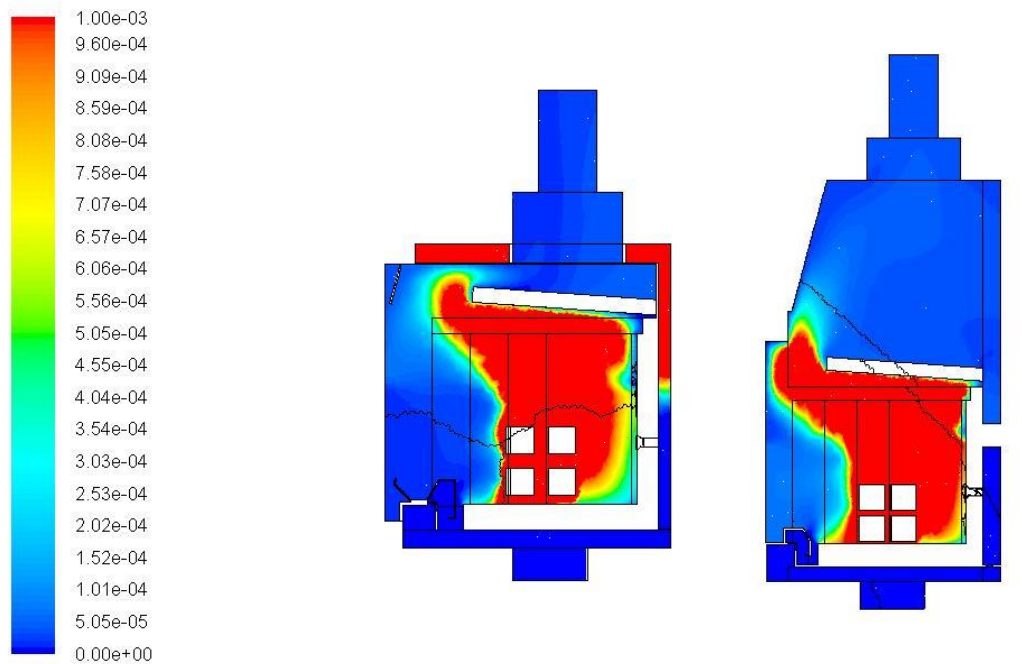

Fig. 6. Concentration of $\mathrm{CO}$ (mole fraction) for case 0 and case 1
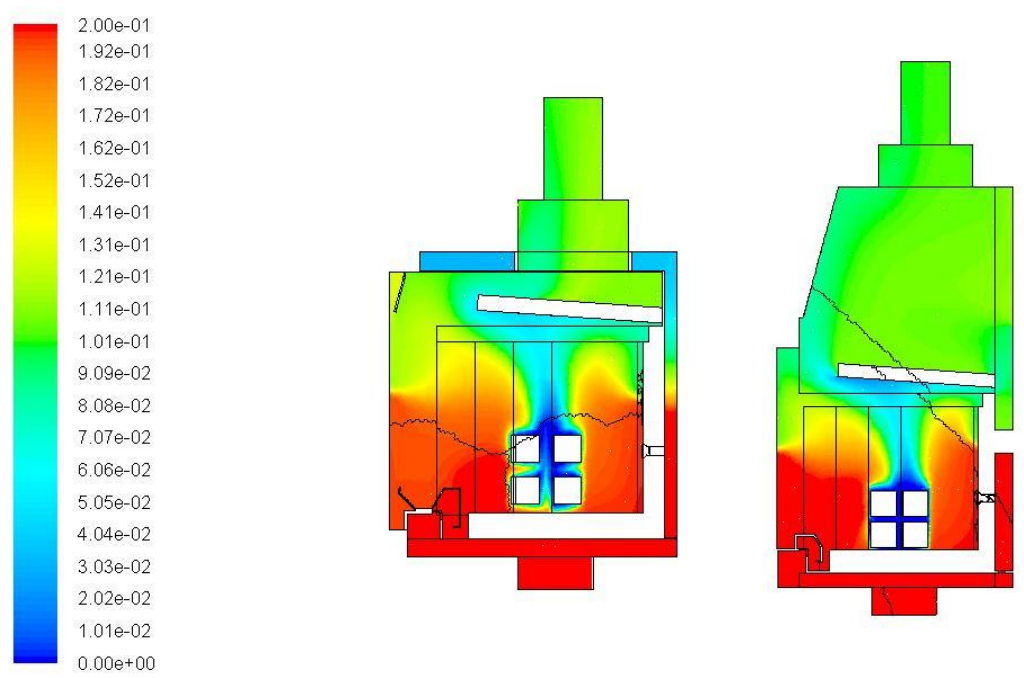

Fig. 7. Concentration of $\mathrm{O}_{2}$ (mole fraction) for case 0 and case 1

Figures 5-7 present the distribution of gas molecules along with the temperature scale as well as the predicted $\mathrm{CO}$ and $\mathrm{O}_{2}$ concentrations in selected areas of the fireplace insert. The gas molecules in Fig. 5a (case 0) confirm vertical flame propagation that could be observed during a bench experiment. While in the case of a modified construction, the redesigned flue gas chamber facilitates elongation of the exhaust gas path in the temperature zone ensuring the combustion of the remaining combustible gases in the exhaust gas and minimal CO emission to the chimney. The obtained swirling of exhaust an intense heat exchange with the environment and thus a reduction in the temperature of the flues in the chimney, which is directly related to the improvement of the efficiency of the modified fireplace insert. In both cases (case 0 and case 1) it should be emphasized that the holes in the back wall of the focal chamber fulfil their role of eliminating zones with high concentration of $\mathrm{CO}$. This treatment is necessary because the furnace chamber is 
characterized by large changes of temperature and the resulting lower temperature zone and high $\mathrm{CO}$ concentration can affect the emission standards obtained in the chimney.

\section{Summary}

The need to implement many models of heating installations up to $20 \mathrm{~kW}$ with similar parameters with systematically tightened environmental standards makes numerical modelling of combustion processes and heat exchange is becoming an interesting method of rapid prototyping. The proposed computational technique, despite the introduction of model simplifications, allows obtaining numerical data for newly designing construction within a few to several hours with the assumption of a numerical grid of 3-4 million elements. Comparing the modified construction (case 1) to the output variant (case 0), design changes in the final design were recommended. The redesign of the smoke conduit to increase the heat exchange surface and flue gas turbulence, as well as modification of the air supply ducts to the rear wall of the combustion chamber, contributed to the lowering of the flue gas temperature, and thus the reduction of the chimney losses of the installation.

\section{Acknowledgment}

The authors would like to gratefully acknowledge the financial support through the Grant No. POIG.01.04.00-14-351/13 financed by the National Centre for Research and Development - Poland

\section{References}

1. Krzysztof Sornek, Mariusz Filipowicz, Kamila Rzepka, Study of clean combustion of wood in a stove-fireplace with accumulation, Journal of the Energy Institute 90 (2017) 613-623

2. Ricardo L. Carvalho, Estela D. Vicente, Luís A.C. Tarelho, Ole M. Jensen, Wood stove combustion air retrofits: A low cost way to increase energy savings in dwellings, Energy \& Buildings 164 (2018) 140-152

3. Scharler R., Benesch C., Neudeck A., Obernberger I., CFD based design and optimization of wood log fired stoves, 17th European Biomass Conference and Exhibition, From Research to Industry and Markets 29 June - 03 July 2009, Hamburg, Germany

4. Menghini D., Marchione T., Martino G., Marra F., Allouis C., Beretta F., Numerical and experimental investigations to lower environmental impact of an open fireplace, Experimental Thermal and Fluid Science 31 (2007) 477-482

5. Mette Bugge, Øyvind Skreiberg, Nils Erland L. Haugen, Morten Seljeskog, CFD modelling of NOx emissions from wood stoves, Proceedings of the 1st International Workshop on CFD and Biomass Thermochemical Conversion Leipzig, Germany, 30 September 2014

6. ANSYS® Fluent, Release 19, Help System, ANSYS, Inc.

7. The standard EN 13229:2001/A1:2003/A2:2004/AC:2007 